\title{
Virtual Observation Environment for Training and Monitoring of Insurance Software End-Users
}

\author{
Jurijs Lavendels ${ }^{1}$, Mikola Krischuk ${ }^{2}$, Vjaceslavs Sitikovs ${ }^{3}$, Zigmunds Bulins ${ }^{4}$ \\ ${ }^{1,3,4}$ Riga Technical University, ${ }^{2}$ National Technical University of Ukraine
}

\begin{abstract}
Technological tools for the mastering of insurance software product remotely by end-users are described. To ensure distance training, two independent channels have been simultaneously used: one for video-audio conference providing trainer-trainee(s) communication and second one for collaboration between a trainer and trainee(s) showing software execution and control over trainee's working with the software. The proposed solution has been approbated in several focus groups that give an evidence of its practical viability and applicability.
\end{abstract}

Keywords - Insurance software, interactive distance training remote users, server remote control.

\section{INTRODUCTION}

Software for the support of insurance operations is one of the most complicated in the IT industry [1]. Various potential cases have to be taken into consideration and reflected in the developed software products, including appropriate interface for end-users (insurance end- and front-office staff). Usually, the process of implementing of new software (or newly elaborated version of a previous product) requires the scrupulous training of end-users. For insurance companies with a divaricate network of branches and outlets, it is not always easy to divert the staff from on-going operations and to arrange massive training in classrooms. It is also not easy to arrange trips to remote locations for training staff (usually representatives of IT departments) on-site.

Therefore, the implementation of remote tool(s) is of high importance for insurance software perfection and upgrading because it provides an opportunity not only to show how new software works, but also to instruct/coach trainees, monitor their work and if necessary to correct wrong actions.

We are engaged in the organization and technical support of interactive distance sessions, including presentations on mastering a product and monitoring/control of remote enduser's operations. For this purpose, we have taken the following steps: a) the examination of potential tools not requiring installation of additional software on end-users' side for the provision of interactive distance training; b) the implementation of these tools.

\section{REQUIREMENTS FOR THE TOOLS PROVIDING INTERACTIVE TRAINING}

In the case of distance training, the trainer-trainee(s) collaboration must be sufficiently convenient [2]. For presentation of innovations, it is necessary to provide:
- listener-presenter audio communication. This type of communication delivers the content, listener's questions and enables discussions;

- listener-presenter visual communication, where the listener could see the presenter and the presenter could see listener(s). This type of communication stimulates the most appropriate speed of presentation, helps to maintain listeners' interest and so on;

- presentation of software usage.

During the practicum (hands-on training), in addition to the items listed above, means (tools) for trainer-trainee collaboration should also be provided to complete tasks using the software environment. It is necessary to note that in the case of classroom lessons the trainer has an opportunity to observe participants' work at their computers and has an opportunity to advise a trainee directly on the basis of seen operations on the screen, including demonstration of particular necessary manipulations.

\section{DESCRIPTION OF THE SOLUTION}

Implementing the four European Social Fund projects in Latvia [3], [4], [5], [6], we pointed out two parallel channels operating in collaboration (Fig. 1):

- channel for audio and video transmission (audio communication for trainer's voice, trainees' questions, discussions and the video communication for broadcasting of trainer's image to trainees and vice-versa trainee's or auditorium image to a trainer);

- channel for presentation and collaboration (presentation of slides, demonstration of practical manipulations, monitoring of trainee's performance during completeness of assigned tasks, analysis of trainees' work and individual assistance).

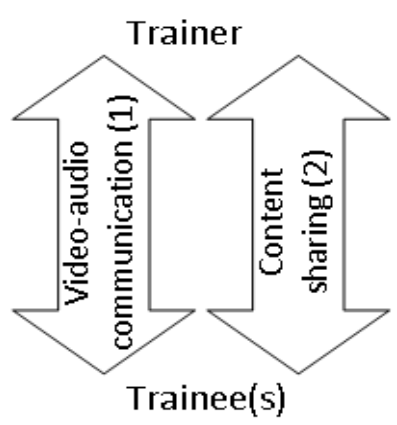

Fig. 1. Schematic diagram of Trainer-Trainee(s) collaboration. 
Voice and video channel could be implemented by the use of Internet communication tools such as Skype. The channel for presentation of the considered issues and for cooperation (actually for application sharing - working with the same instantiation of software product) could be implemented by different means on the Internet. On the logical level, this channel is implemented as an imaginary (virtual) computer, hereinafter called as "cooperative computer", which has two controls: one on the remote trainer's side and one on the remote trainee's side (Fig. 2). Depending on the type of lessons - presentation in one auditorium, simultaneous presentation to several auditoriums, software demonstration, trainee's control, consultation, etc. - the channel for presentation could be implemented by a variety of different means, giving to the channel slightly different properties.

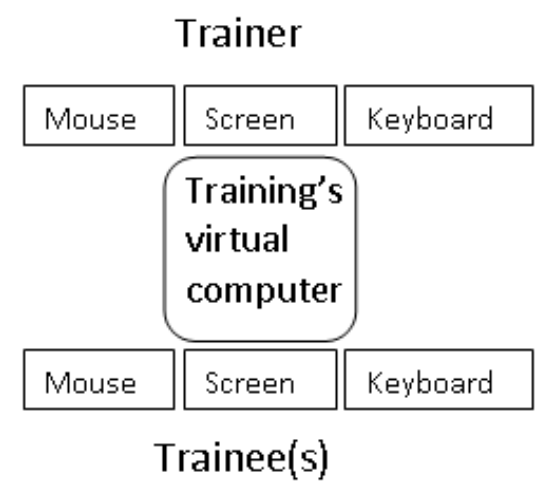

Fig. 2. Model of virtual computer for mastering of software product.

\section{EXAMPLES OF POSSIBLE IMPLEMENTATION OF DisTANCE TRAINING MEANS}

Examples of implementation for provision of remote presentations and remote hands-on training are described below.

\section{A. Simultaneous Presentations in Several Classrooms}

The simplest means for simultaneous presentation to a number of audiences could be Skype in "screen sharing" mode in combination with "High Speed Conferencing Service" [7].

Simultaneous presentations in a number of audiences can be provided using separate channels for audio and video transmission (presenter's voice and image) and channel broadcasting presentation. In this case, the presentation material (e.g., PowerPoint presentation) is posted on the server during the session. An audience connects to the server and presentation is projected on the screen.

However, in such a solution the trainer cannot see particular participant's work with the program; therefore, interactive collaboration between the trainer and the trainee is actually lost. As a consequence, for distant hands-on training such an approach does not work.

\section{B. Usage of PC Remote Control}

To enable work of the trainer and trainee on the same software unit (program) on the basis of a remotely controlled computer, there are two possibilities:
- taking over the control of trainee's computer;

- taking over the trainee's terminal session on a server.

\section{Remote Control of Trainee's $P C$}

Taking over the control of trainee's computer has the following shortcoming - the screen of the computer is seen either by the trainee (normal work) or by the trainer (remote control). It means that the trainer can correct the mistakes the trainee has made, but the trainee does not see this process. At the same time, when the trainee is working with the program, the trainer does not see what the trainee is doing.

\section{Remote Control of Server's Session}

More complicated, but at the same time more efficient alternative is taking over the trainee's terminal session on a server (Fig. 3). In this case, the necessary working environment is created in the following order:

- at first, the trainee starts a remote terminal session on a server;

- then the trainer (having the required access rights) takes over the control of the trainee's session.

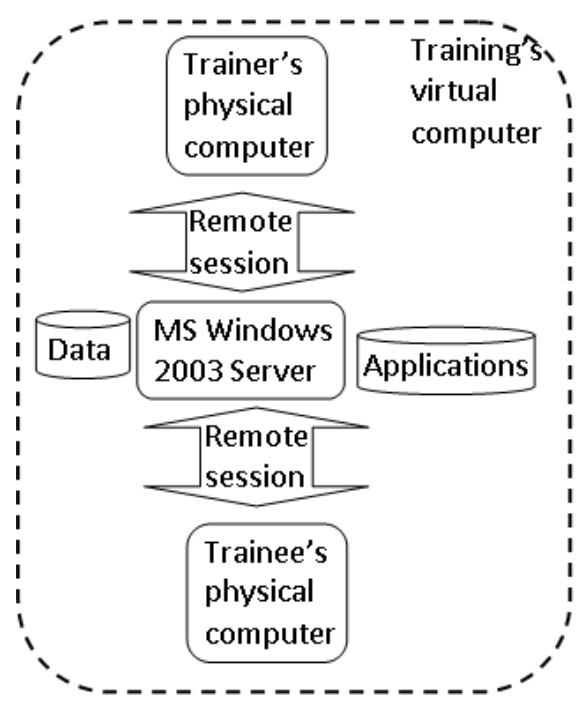

Fig. 3. Topology of virtual training computer based on remote sessions to the server.

This way, both the trainee and the trainer see the same session's screen (desktop of the server and all applications running on the server). Both sides are able to control the process and the mouse pointer is seen all the time for both sides.

\section{V.CREATION OF VIRTUAL LESSON’S COMPUTER}

The necessary working environment is created in the following order. Firstly, the trainee starts a remote terminal session on a server creating "trainee's virtual computer" (Fig. 4).

Then the teacher (having administrator's access rights) intercepts control of the "trainee's virtual computer" creating thus "training virtual computer" (Fig. 5). 


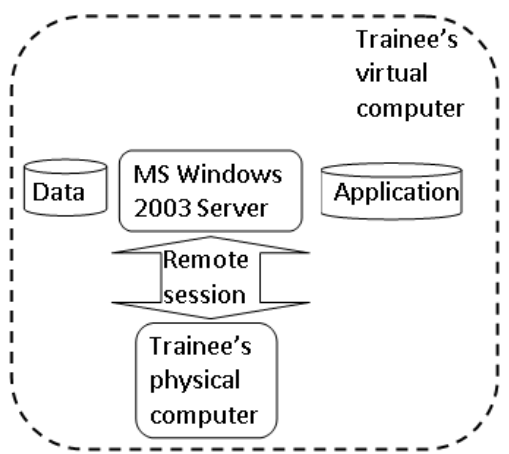

Fig. 4. Topology of trainee's virtual computer after connection to the server

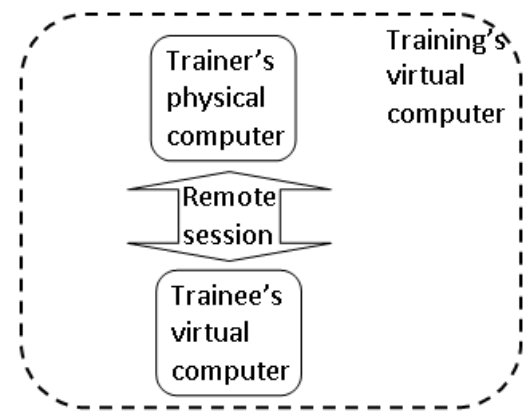

Fig. 5. Topology of training session virtual computer after interception of trainee's remote session on the server by the trainer.

This way, both the student and the teacher see the same session's screen (desktop of the server and all the applications running on the server). Both sides are able to control the process and the mouse pointer is seen all the time.

In the case of MS Windows 2003 Server, to intercept the existing remote session on the server [8] it is necessary to open "Terminal Services Management" window and positioning cursor over the existing student's session to open "right-click" menu and select "Remote Control" (Fig. 6).

The approach described in the paper provides possibilities for two people to work at the same computer. In the remote training, it is very important because, basically, there are no essential difficulties to arrange a video conference for a presenter and a listener, but it is much more important to enable both these participants to work at the same application and to correct trainee's mistakes and to show by the trainer good practice of using the software.

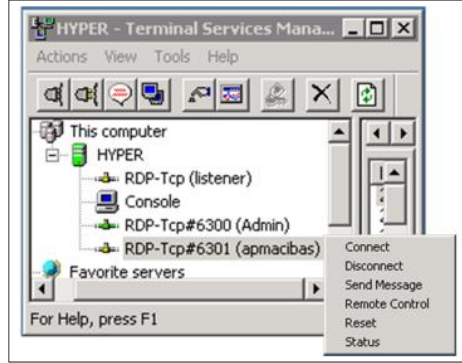

Fig. 6. Interception of trainee's session on the server by the trainer with administrator's rights.

\section{APPROBATION OF THE SOLUTION}

As it is not possible to test the newly developed approach in the real working environment, we have implemented tools described above in the training course for secondary school teachers mastering MOODLE learning management system [6]. Moodle environment has been selected for testing because it has a quite sophisticated user interface (majority of menus, submenus and choices) and, therefore, is very similar (in terms of complexity of user's interface) to insurance applications. Moreover, secondary school teachers are experienced experts in teaching and learning and their considerations regarding usability of approbated tools have a great value. We have worked with five groups of trainees - each group of 10 persons. Sessions were conducted from Riga to seven cities in Latvia.

For the arranging of remote lessons we have used MS Windows 2003 Server, on which the mastering system MOODLE has been installed. Lessons have always been held from Riga - from different places, depending on the trainer. During the lessons, trainees of participating schools in 7 other cities were in computer classes.

On a trainee's computer, both remote server's session and Skype video conference were running. Thus, the trainee simultaneously watched on the screen both the trainer's video and the window with running MOODLE. With each group 5 remote lessons were held, each one and a half hours long.

\section{ASSESSMENT AND IMPROVEMENT}

To assess the acceptability of this approach, after the end of the course the survey of trainees was conducted. In the survey, 33 secondary school teachers who were trained using the virtual remote session platform participated. Some results of the survey are given in Table I.

TABLE I

RESUlts OF THE SURVEY OF VIRTUAL Class PARTICIPANTS

\begin{tabular}{|c|c|c|c|}
\hline & Yes $(\%)$ & $50 / 50(\%)$ & No $(\%)$ \\
\hline Was the quality of video image sufficient? & 80 & 13 & 7 \\
\hline Were the cursor and its movement always visible on the screen? & 79 & & 21 \\
\hline Were the movements of cursor and trainer's voice always synchronized? & 78 & & 22 \\
\hline Was the quality of sound (trainer's voice) adequate? & 67 & & 33 \\
\hline Is it necessary to see video images of the trainer during the session? & 79 & 6 & 15 \\
\hline Did you feel discomfort due to the presence of video camera in front of you? & 3 & 6 & 91 \\
\hline
\end{tabular}




\begin{tabular}{|l|c|c|}
\hline Was the trainer able to regulate the pace of a training lesson? & 91 & 6 \\
\hline Should the pace of virtual presentation be slower than a face-to-face lesson? & 50 & 25 \\
\hline Should the duration of a virtual lesson be shorter than face-to-face training? & 21 & 58 \\
\hline Are you in general satisfied with such an environment and the method of a virtual lesson? & 84 & 10 \\
\hline
\end{tabular}

In addition, views of respondents regarding the duration of the virtual session are given in Table II.

TABLE II

DESIRED LENGTH OF THE VIRTUAL SESSION

\begin{tabular}{|l|l|l|l|l|}
\hline $\begin{array}{l}\text { Frequency of } \\
\text { responses }\end{array}$ & 30 minutes & 40 minutes & 60 minutes & 90 minutes \\
\cline { 2 - 5 } & $15 \%$ & $54 \%$ & $23 \%$ & $8 \%$ \\
\hline
\end{tabular}

A brief analysis of the presented results shows that [9], [10]:

- For a trainee it is important to see the video of the trainer;

- The approach provides sufficient technical quality, even in places with a rather low speed of Internet connection.

It is possible to improve and accelerate the process of new software mastering by arranging trainees in groups. If it is possible to gather in one auditorium several trainees simultaneously, then a projector could be connected to the trainee's computer and the presentation could be watched by everyone in the classroom. The interchange of audio information is done by using Skype and, if available, Skype is used for a video call. In this case, the trainer can watch the audience, and the audience sees its trainer. For hands-on training or consultations (tutorials), from the audience's side just a single trainee works at the "cooperative computer" and the trainer interacts just with him/her.

\section{CONCLUSIONS}

Practical approbation of the proposed solution shows its high applicability - rating of suitability of different aspects related to distance training was within $69 \%-91 \%$. The most essential is that $84 \%$ of participants were completely satisfied with the implemented approach.

There is no need to use two computers at each of the sides in order to carry out remote sessions - combining two screens on one monitor provides a sufficient technical quality. In addition, this quality does not depend on the location of the trainer during the session.

\section{ACKNOWLEDGEMENTS}

The research has been funded by the ERDF (ERAF) project No. 2011/008/2DP/2.1.1.1.0/10/APIA/VIAA/018

"Development of Insurance Distributed Software Based on Intelligent Agents, Modeling, and Web Technologies".

\section{REFERENCES}

[1] L. Novitsky, E. Viktorova. "Integrated Insurance Information Systems: State of the Art - a Survey". The International Workshop ICTI'98. Information and Communication Technologies for Insurance. Riga: RTU, 1998. pp. 27-35.

[2] G. Jekabsons, K. Krauklis, J. Lavendels, V. Sitikovs, "Effectiveness of e-learning implementation and prospects of its advancements for distributed groups of learners". Education Quality, Magazine of the
Institute of Applied Computer Systems of Riga Technical University, Riga, Latvia, Riga Technical University, 2010. pp. 5-12.

[3] J. Lavendels, V. Sitikovs, E. Latisheva. "Collaboration Tools for The Fostering of Learning Process of Disabled Youth". Proceedings of 6th International Conference "Virtual University VU'05”, 2005. ISBN 80227-2336-3J. Lavendels, V. Sitikovs, K. Krauklis, "Technological Solution for On-Line Teaching of Latvian Provinces", Proceedings of “EDEN 2008” Annual Conference, 11-14 June 2008, Lisbon, Portugal, ISBN 978-963-87914-0-5

[4] J. Lavendels, V. Sitikovs, K. Krauklis. "Informational Technologies for Further Education of Latvian Province Teachers of Informatics". Mittermeir, R.T. and Syslo M., M. (ed.) ISSEP 2008. LNCS, vol. 5090, pp. 349-356.

[5] The Latvian Language Agency. "The project "The Latvian language and literature, and bilingual education teachers' professional competence improvement", Retrieved from: http://www.valoda.lv/ESF_projekti/ Latviesu_valodas_literaturas_un_bilingvalo_macibu_pedagogu_profesio nalas_kompetences_pilnveide /793/mid 527

[6] K. Krauklis, V. Shitikov, "Solutions of collaboration process provision in the VOIP Skype environment". Proceedings of International Scientific Practical Conference „Information \& Communication Technology in Natural Science Education. 2-5 December 2007, Šiauliai, Lithuania, ISBN 978-9986-38-823-4, pp. 93-98

[7] How to enable and to configure Remote Desktop for Administration in Windows Server 2003, Retrieved from: http://support.microsoft.com/kb/814590

[8] J. Lavendels, V. Sitikovs, J. Steinmanis. "Using remote server control to provide virtual classes". Education and Virtuality-VIRT-2011, 19-23 September, Yalta, pp. 77-82 (In Russian).

[9] Bulins Z., Krauklis K., Lavendels J., Sitikovs V., Steinmans J. Implementation and observation of interactive Distance Teaching WCCE 2013 10th IFIP World Conference on Computersin Educatio, Torun, Poland; July 1-7, 2013 Vol.2,p.128-135

Jurijs Lavendels graduated from Riga Technical University (previously Riga Polytechnic Institute) in 1975. In 1987 he received a degree of Dr.sc.ing. in Engineering Sciences. Jurijs Lavendels is a Professor of Riga Technical University, experienced Computer Science Instructor and the Head of Informatics and Programming Department of Riga Technical University. Main scientific interests include computer aided teaching, learning and training. Most important scientific project - UNITE: 26964 (FP6-2004-IST-4) Unified eLearning environment for the school 01/02/2006 - 31/07/2008 E-mail: jurijs.lavendels@rtu.lv

Mikola Krischuk graduated from Kiev Polytechnical Institute in 1979. In 1986 he received a degree of Dr.sc.ing. in Machinery Construction. In 1986, he received a degree of Dr.hab.sc.ing. in Machinery Construction. Mikola Krischuk is a Professor of the National Technical University of Ukraine.

E-mail: krys@ukr.net

Vjaceslavs Sitikovs graduated from Riga Technical University (previously Riga Polytechnic Institute) in 1973. In 1982 he received a degree of Dr.sc.ing. in Technical Cybernetics. Vjaceslavs Sitikovs is an Associated Professor of Riga Technical University. He is an experienced Computer Science Instructor and Specialist in Project Management. In recent years, he has managed a set of large-scale international projects related to different kinds of teaching and learning. He is an expert of several funds and member of several international conference program committees.

E-mail: vjaceslavs.sitikovs@rtu.lv

Zigmunds Bulins graduated from Riga Technical University and received the degree of Master of Science in 2011. Zigmunds Bulins is a highly-qualified Computer Science Specialist. His main areas of research are the security of information systems and "cloud computing" technology.

E-mail: zigmund.bulinsh@rtu.lv 